\title{
Excessive Ventilation After Acute Myocardial Infarction and Its Improvement in 4 Months
}

\author{
Toru Satoh, MD; Yoshiaki Okano, MD; Hiroshi Takaki, MD; \\ Takahiro Matsumoto, MD; Yoshio Yasumura, MD; \\ Naohiko Aihara, MD; Yoichi Goto, MD
}

\begin{abstract}
The relationship between ventilation $(\mathrm{VE})$ and $\mathrm{CO}_{2}$ output $\left(\mathrm{VCO}_{2}\right)$ is fitted linearly. The steeper gradient implies excessive ventilation. Through an evaluation of the $\mathrm{VE}_{\mathrm{E}}-\mathrm{V}_{\mathrm{CO}}$ slopes, this study investigated whether patients with acute myocardial infarction (AMI) have excessive ventilation and whether it improved in 4 months. The $\mathrm{VE}_{\mathrm{E}}-\mathrm{V}_{\mathrm{CO}} 2$ slopes were determined in exercise tests at 1 and 4 months in 131 patients with AMI. Patients were divided into 3 groups according to the 1 month $\mathrm{VE}_{\mathrm{E}}-\mathrm{V}_{\mathrm{CO}}$ slope value: (i) normal (<30); (ii) intermediate (30-32); and (iii) excessive ( $>32)$. In the normal group $(n=76)$, at 4 months, the slope decreased in 10, increased in 5 and remained unchanged in 61 patients; in the intermediate $(n=31)$ group, 9, 2 and 20; and in the excessive $(n=24)$ group, 15, 3 and 6 , respectively, showing that the slope reduction was greater in the excessive group $(\mathrm{p}<0.01)$. The slope correlated with age and acute phase heart failure. The percent reduction of the slope did not correlate with these parameters. In conclusion, a substantial fraction of patients with AMI have excessive ventilation that improves in 4 months. The improvement is greater in patients with greater excessive ventilation but is not associated with an improvement in exercise capacity nor hemodynamics. (Jpn Circ J 2001; 65: 399-403)
\end{abstract}

Key Words: Cardiac rehabilitation; Exercise test; Ventilatory response; $\mathrm{VE}_{\mathrm{E}}-\mathrm{V}_{\mathrm{CO}}$ slope

D yspnea on exertion is associated with excessive ventilatory response to exercise in patients with cardiac or pulmonary diseases. Ventilatory response to exercise has been evaluated using the gradient of the relationship between ventilation $\left(\mathrm{VE}_{\mathrm{E}}\right.$ ) and carbon dioxide output $\left(\mathrm{V}_{\mathrm{CO}_{2}}\right)$ in many reports ${ }^{1-3}$ and with high reproducibility? Because ventilation is promoted to maintain the arterial concentration of $\mathrm{CO}_{2}$, the $\mathrm{VE}-\mathrm{V}_{\mathrm{CO}}$ relationship is fitted linearly until the respiratory compensation point, when $\mathrm{VE} / \mathrm{V}_{\mathrm{CO}_{2}}$ starts to increase and end-tidal carbon dioxide partial pressure starts to decrease, near the point of maximal exercise. 4 Because of this linearity, the slope of the $\mathrm{VE}_{\mathrm{E}}-$ $\mathrm{V}_{\mathrm{CO}}$ relationship can be easily determined regardless of the patient's effort. The slope correlates with dead space ventilation ratio $\left(\mathrm{VD}_{\mathrm{D}} / \mathrm{VT}\right)$, , which is augmented by the reduced pulmonary flow relative to ventilation. It has also been reported that ventilatory response to exercise is elevated in several morbid conditions such as pulmonary hypertension ${ }^{6}$ pulmonary diseases ${ }^{7}$ and severe left ventricular dysfunction?

In contrast, ventilatory response to exercise is known to be greatly improved after cardiac transplantation? Also, gradient measurement has been used to assess the effect of exercise therapy for patients with heart failure ${ }^{9}$ or pulmonary diseases 10 Niederman reported that only excessive ventilatory response was ameliorated after rehabilitation in patients with obstructive pulmonary disease, without an

(Received August 23, 2000; revised manuscript received December 20, 2000; accepted January 18, 2001)

Division of Cardiology, Department of Medicine, National Cardiovascular Center, Osaka, Japan

Mailing address: Toru Satoh, MD, Cardiopulmonary Division, Department of Medicine, Keio University School of Medicine, 35 Shinanomachi, Shinjukuku, Tokyo 160-8582, Japan. E-mail: tsatoh@ cpnet.med.keio.ac.jp improvement in resting pulmonary function 10

There have been no reports about the ventilatory response to exercise soon after an acute phase in patients with acute myocardial infarction (AMI) and its alteration during the chronic phase. In the present study, we aimed to clarify whether ventilatory response to exercise is increased after AMI and, if so, whether it is improved in a few months. We assessed ventilatory responses to exercise in 131 patients with AMI after participating in a 3-month cardiac rehabilitation program. The patients routinely underwent exercise tests before and after exercise. Also, the relationship between $\mathrm{VE}_{\mathrm{E}}$ and $\mathrm{V}_{\mathrm{CO}}$ and other clinical parameters were analysed to determine which factors altered ventilatory response.

\section{Methods}

\section{Patients}

Of 172 patients who suffered from AMI, we studied 131 patients who completed a 3-month rehabilitation program and underwent exercise tests 1 month before rehabilitation and 4 month post-rehabilitation, at the National Cardiovascular Center in Japan. The remaining 41 patients were those who did not participate in the rehabilitation program and did not take both exercise tests because of some disability or difficulty affecting participation. Patients who were either older than 76 years, had persistent congestive heart failure, suffered exercise-induced myocardial ischemia, or had serious arrhythmia were excluded from the rehabilitation program. The average age of patients who participated in the program was $60 \pm 9$ (range 26-75) years. There were 108 male and 23 female patients. The left ventricular ejection fraction measured by the left ventriculography 1 month after the onset of AMI was $49 \pm 11 \%$. Phase 2 of the cardiac rehabilitation program was commenced $23 \pm 13$ 
days (median 18 days) after the onset of AMI. The first exercise test was performed $35 \pm 16$ days (median 30 days) and the second test $119 \pm 22$ days (median 116 days) after AMI. Congestive heart failure in the acute phase was noted in 18 patients. All patients understood the purpose and the procedure of the study, and gave written informed consent.

\section{Exercise Test}

Within 2 weeks of starting the cardiac rehabilitation program and at 3 months, symptom-limited spiroergometry was performed using the breath-by-breath method with an AE-280 spiroergometer (Minato Co, Ltd, Osaka, Japan) while being monitored by an electrocardiogram and blood pressure. Patients pedaled at $55 \mathrm{rpm}$ without added load for $1 \mathrm{~min}$. The work rate was then increased by $15 \mathrm{~W}$ per minute until the point of exhaustion. $\mathrm{VE}$, oxygen uptake $\left(\mathrm{VO}_{2}\right)$ and $\mathrm{VCO}_{2}$ were measured.

\section{Evaluated Variables}

To evaluate ventilatory responses to exercise, the gradient of the $\mathrm{VE}_{\mathrm{E}}-\mathrm{V}_{\mathrm{CO}}$ 2 relationship (Fig 1) was determined. The $\mathrm{VE}-\mathrm{V}_{\mathrm{CO}}$ slope was able to be linearly regressed in all patients until the respiratory compensation point, which is when $\mathrm{VE} / \mathrm{V}_{\mathrm{CO}_{2}}$ starts to increase and end-tidal carbon dioxide partial pressure starts to decrease, with regression coefficients higher than 0.95 . Patients were divided into 3 groups according to the $\mathrm{VE}-\mathrm{VCO}_{2}$ slope at 1 month: (i) normal ventilatory response group $\left(\mathrm{VE}_{\mathrm{E}}-\mathrm{V}_{\mathrm{CO}} 2\right.$ slope $<30$, $\mathrm{n}=76$ ); (ii) intermediate ventilatory response group (30 $\leq$ $\mathrm{VE}_{\mathrm{E}}-\mathrm{V}_{\mathrm{CO}}$ slope $\leq 32, \mathrm{n}=31$ ); and (iii) excessive ventilatory response group $\left(32<\mathrm{VE}_{\mathrm{E}}-\mathrm{VCO}_{2}\right.$ slope, $\left.\mathrm{n}=24\right)$. From our previous data, $95 \%$ of 107 healthy people $(52 \pm 17$ years) were included below the $\mathrm{VE}-\mathrm{VCO}_{2}$ gradient measurement of 30 . Healthy people were never included above the slope measurement of 32. The slopes at 1 month and at 4 months after AMI were compared for each patient. If the slope was statistically significantly decreased, ventilatory response was defined as improved, and vice versa. To investigate the factors influencing the improvement in ventilatory response, the relationships between the $\mathrm{VE}_{\mathrm{E}}-\mathrm{VCO}_{2}$ slope and age; the left ventricular ejection fraction and end-diastolic pressure, which was measured by cardiac catheterization 1 month

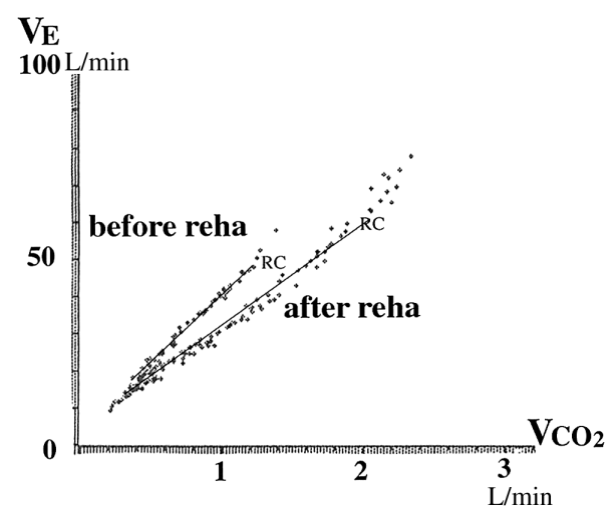

Fig 1. Relationship between ventilation and $\mathrm{CO}_{2}$ output $\left(\mathrm{VE}-\mathrm{VCO}_{2}\right)$ at 1 month and 4 months after acute myocardial infarction (AMI) (a representative case). Ventilation is plotted against $\mathrm{V}_{\mathrm{CO}_{2}}$ for a 64-yearold male patient with acute inferior myocardial infarction (left ventricular ejection fraction 54\%). Both plottings are linearly regressed until the RC (respiratory compensation) point. The left side of the plot is at 1 month and the right side is at 4 months after AMI. The regressed slope of the $\mathrm{VE}-\mathrm{VCO}_{\mathrm{CO}}$ relationship is significantly reduced from 39 to 26 in 3 months with the aid of cardiac rehabilitation. The unit of the slope is determined by representing the units of $\mathrm{VE}$ and $\mathrm{VCO}_{2}$ as $\mathrm{L} / \mathrm{min}$.

after the onset of myocardial infarction; and the presence or absence of congestive heart failure in the acute phase and peak $\mathrm{VO}_{2}$ were evaluated.

\section{Cardiac Rehabilitation Program}

After completing phase 1 of the cardiac rehabilitation program in the coronary care unit, patients underwent submaximal treadmill exercise tests at a heart rate up to $75 \%$ of the maximum. When the results were negative for ischemia, patients were allowed to enter phase 2 of the rehabilitation program. The program consisted of walking, calisthenics and bicycle ergometer for $90 \mathrm{~min}$, including warm-up and cool-down, 5 days a week under supervision while patients were in hospital. After being discharged, patients exercised 3-5 times a week, which included a combination of gymnasium exercise at the rehabilitation facility and home exercise. Home exercise protocol was

Table 1 Clinical Characteristics in the 3 Groups With Different $\mathrm{VE}_{\mathrm{E}} \mathrm{V}_{\mathrm{CO}_{2}}$ Slopes

\begin{tabular}{|c|c|c|c|c|}
\hline & Normal & Intermediate & Excessive & Overall \\
\hline No. patients & 76 & 31 & 24 & 131 \\
\hline Age (years) & $58 \pm 10$ & $62 \pm 9$ & $66 \pm 6 * \dagger$ & $60 \pm 9$ \\
\hline Male (\%) & 84 & 84 & 79 & 82 \\
\hline$B M I$ & $23 \pm 2$ & $23 \pm 3$ & $22 \pm 3$ & $23 \pm 3$ \\
\hline Presence of $\mathrm{CHF}(n)$ & 7 & 2 & 7 & 16 \\
\hline Presence of $\mathrm{CHF}(\%)$ & 9 & 6 & $29 * \dot{*}$ & 12 \\
\hline $\operatorname{Max} C K$ & $2,994 \pm 2,659$ & $3,294 \pm 3,123$ & $4,312 \pm 3,052$ & $3,328 \pm 2,861$ \\
\hline$E F(\%)$ & $50 \pm 10$ & $50 \pm 11$ & $46 \pm 12$ & $49 \pm 11$ \\
\hline LVEDP (mmHg) & $12 \pm 6$ & $13 \pm 7$ & $13 \pm 6$ & $13 \pm 6$ \\
\hline 1-month $\mathrm{VE}_{\mathrm{E}}-\mathrm{V}_{\mathrm{CO}}$ & $26 \pm 2$ & $31 \pm 1 *$ & $35 \pm 2 * 广$ & $29 \pm 4$ \\
\hline 4-month $V_{E}-V_{C O_{2}}$ & $26 \pm 3$ & $30 \pm 3 *$ & $32 \pm 4 * \dagger$ & $28 \pm 4$ \\
\hline 1-month peak $\mathrm{VO}_{2}\left(\mathrm{ml} \cdot \mathrm{min}^{-1} \cdot \mathrm{kg}^{-1}\right)$ & $22 \pm 4$ & $21 \pm 4$ & $18 \pm 3 * \dagger$ & $21 \pm 4$ \\
\hline 4-month peak $\mathrm{VO}_{2}\left(\mathrm{ml} \cdot \mathrm{min}^{-1} \cdot \mathrm{kg}^{-1}\right)$ & $26 \pm 4$ & $24 \pm 5$ & $21 \pm 4 * \dagger$ & $25 \pm 5$ \\
\hline Peak $\mathrm{VO}_{2}$ improvement $(\%)$ & $19 \pm 21$ & $13 \pm 22$ & $18 \pm 18$ & $18 \pm 20$ \\
\hline Days from AMI to REHA & $24 \pm 18$ & $22 \pm 12$ & $22 \pm 16$ & $23 \pm 13$ \\
\hline
\end{tabular}

Data are presented as mean $\pm S D ; * p<0.05$ compared with normal group; ${ }^{\dagger} p<0.05$ compared with intermediate group. BMI, basal metabolic index; $C H F$, congestive heart failure; max CK, maximal creatine kinase; EF, ejection fraction; LVEDP, left ventricular end-diastolic pressure; 1-month, 1 month after AMI; 4-month, 4 months after AMI; peak VOz improvement, percentage of improvement in the peak $\mathrm{VO}_{2}$ in 3 months; Days from AMI to REHA: the number of days from the onset of AMI to the start of phase 2 cardiac rehabilitation. 


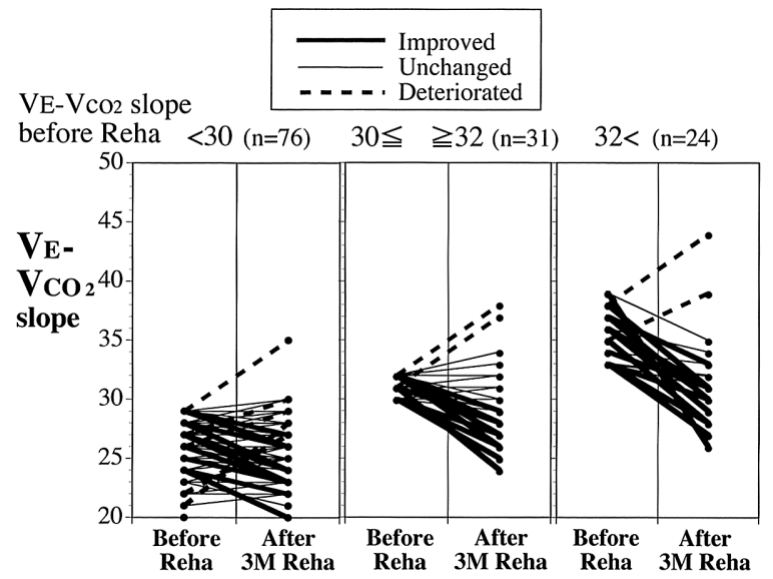

Fig 2. Change in the slope of the linear relationship between ventilation and $\mathrm{CO}_{2}$ output $\left(\mathrm{VE}_{\mathrm{E}}-\mathrm{V}_{\mathrm{CO}}\right)$ in 3 months. The $\mathrm{VE}-\mathrm{V}_{\mathrm{CO}}$ slopes at 1 month after AMI for 131 patients were divided into 3 groups ( $\mathrm{VE}-$ $\mathrm{V}_{\mathrm{CO}} 2$ slope $<30 ; 30 \leq \mathrm{VE}_{\mathrm{E}}-\mathrm{V}_{\mathrm{CO}} 2$ slope $\leq 32 ; 32<\mathrm{VE}_{\mathrm{E}}-\mathrm{V}_{\mathrm{CO}}$ s slope). A statistically significant reduction in the slope at 4 months after AMI was considered as an improved ventilatory response. Statistically, no significant change was defined as unchanged and significant elevation as deteriorated.

prescribed individually to attain a target heart rate, which was calculated according to Karvonen's equation as (peak heart rate - resting heart rate) $\times 0.6+$ resting heart rate, obtained during the symptom-limited exercise test before discharge.

\section{Statistics}

Data are shown as mean $\pm \mathrm{SD}$. To compare the $2 \mathrm{VE}-$ $\mathrm{VCO}_{2}$ slope relationships at 1 and 4 months, analysis of covariance (ANCOVA) (statistical software STATFLEX, Viewflex Co, Ltd, Tokyo, Japan) was used. Comparisons of parameters among the groups were performed by analysis of variance (ANOVA) and chi-square test. Comparisons of paired parameters at 1 and 4 months were done by paired t-test. To determine whether the independent variables contributed to the $\mathrm{VE}_{\mathrm{E}}-\mathrm{VCO}_{2}$ gradient, multiple regression analysis was used. A p value less than 0.05 was considered significant.

\section{Results}

Characteristics of Patients With Excessive

Ventilation at 1 Month After AMI

Table 1 summarizes the clinical characteristics of the 3 groups. Patients in the excessive ventilatory response group were older, and showed a higher incidence of congestive heart failure in the acute phase. Although there were no significant differences in the left ventricular ejection fraction or end-diastolic pressure among the 3 groups, the excessive group showed significantly lower values for peak $\mathrm{VO}_{2}$ at 1 and 4 months after AMI compared to the other 2 groups. However, the percentage of improvement in peak $\mathrm{VO}_{2}$ was similar among the 3 groups. Duration from the onset of AMI to the start of phase 2 of the rehabilitation program did not differ among the 3 groups.

\section{Improvement of Excessive Ventilation}

Fig 1 shows examples of $\mathrm{V}_{\mathrm{E}}-\mathrm{V}_{\mathrm{CO}}$ relationships during symptom-limited spiro-ergometry tests in a representative patient who demonstrated a significant improvement in the

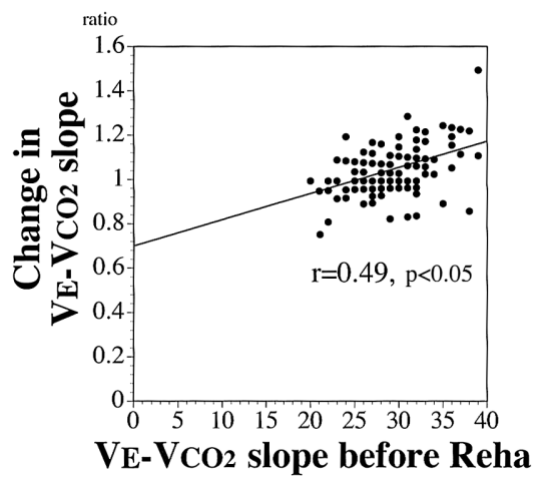

Fig 3. The relationship between ventilation and $\mathrm{CO}_{2}$ output (VE$\mathrm{V}_{\mathrm{CO}}$ ) at 1 month after AMI, and change in the $\mathrm{VE}_{\mathrm{E}}-\mathrm{V}_{\mathrm{CO}}$ gradient. Change in the $\mathrm{VE}_{\mathrm{E}}-\mathrm{V}_{\mathrm{CO}}$ s slope was represented as the ratio of the slope at 4 months compared with the slope at 1 month after AMI.

$\mathrm{VE}-\mathrm{VCO}_{2}$ slope within 3 months. In the normal ventilatory response group $\left(\mathrm{VE}-\mathrm{VCO}_{2}\right.$ slope $\left.<30\right)$, the slope significantly decreased in 10 patients, increased in 5 and remained unchanged in 61 patients. In the intermediate ventilatory response group $\left(30 \leq \mathrm{VE}_{\mathrm{E}}-\mathrm{V}_{\mathrm{CO}}\right.$ slope $\left.\leq 32\right)$, the slope significantly decreased in 9 patients, increased in 2 and remained unchanged in 20 patients. In the excessive ventilatory response group $\left(32<\mathrm{VE}-\mathrm{VCO}_{2}\right.$ slope $)$, the slope significantly decreased in $15(63 \%)$ patients, increased in 2 and remained unchanged in 7 patients (Fig 2). The fraction of patients who showed a reduction in the gradient value within 3 months was significantly greater in the excessive response group compared to the other 2 groups $(\mathrm{p}<0.01$ by chi-square test). As a whole, ventilatory response improved significantly in 34 of 131 patients (26\%).

Fig 3 plots the relationship between the relative reduction in the $\mathrm{VE}-\mathrm{V}_{\mathrm{CO}}$ gradient and the 1 month $\mathrm{VE}-\mathrm{V}_{\mathrm{CO}}$ gradient value in all 131 patients. There was a significant correlation between the 2 variables, indicating that patients with a more excessive ventilatory response to exercise achieved a greater improvement in their response at 4 months after AMI.

\section{Factors Affecting the Worsening and Improvement of Ventilatory Response}

Fig 4 shows the relationship between patients' age and the $\mathrm{V}_{\mathrm{E}}-\mathrm{V}_{\mathrm{CO}}$ slope at 1 month after AMI and the relative improvement in the slope. Although older patients exhibited more excessive ventilatory responses at baseline, improvement in the ventilatory response did not correlate with age. Fig 5 shows the relationship between peak $\mathrm{VO}_{2}$ per bodyweight and the $\mathrm{VE}_{\mathrm{E}}-\mathrm{VCO}_{2}$ slope 1 month after AMI (left panel), and the relationship between improvements in the 2 parameters relative to their respective baseline values. The former 2 parameters were weakly correlated but improvements were not, indicating that improvement in ventilatory response was not associated with an improvement in exercise capacity. Patients with acute phase congestive heart failure $(\mathrm{CHF})$ had a worse ventilatory response than those without $\left(\mathrm{VE}-\mathrm{VCO}_{2}\right.$ slope: $\mathrm{CHF} 32 \pm 4$, no CHF 29 $\pm 4, p<0.05$ ), but improvement in ventilatory response was not influenced by a history of heart failure (improvement in the slope: CHF $6 \pm 11 \%$; no CHF $4 \pm 11 \%$, not significant). Neither left ventricular ejection fraction nor end-diastolic pressure had a significant correlation with the $\mathrm{VE}_{\mathrm{E}}-\mathrm{VCO}_{2}$ slope or an improvement in the slope. 

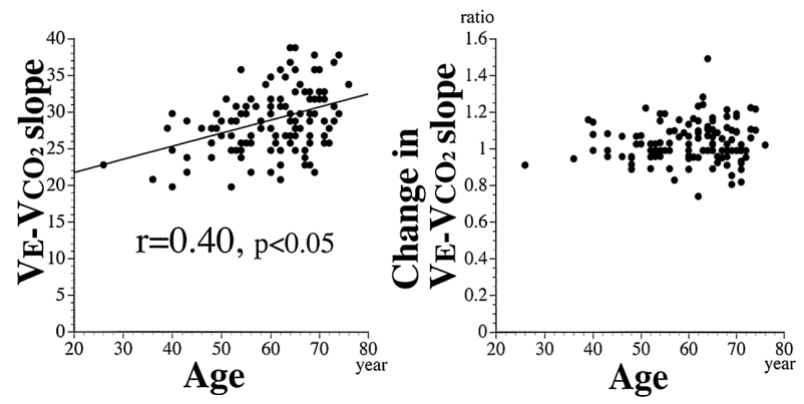

Fig 4. The relationship between a patient's age and $\mathrm{VE}_{\mathrm{E}}-\mathrm{V}_{\mathrm{CO}}$ s slope and its improvement. The left panel shows the relationship between age and $\mathrm{VE}_{\mathrm{E}}-\mathrm{V}_{\mathrm{CO}}$ gradient at 1 month after AMI. The right panel shows the relationship between age and improvement of $\mathrm{VE}-\mathrm{VCO}_{2}$ gradient at 4 months after AMI. The improvement is represented as the ratio of the value at 4 months compared with the value at 1 month after AMI.

When a multiple regression analysis for the 1 month $\mathrm{VE}-\mathrm{VCO}_{2}$ slope as a criterion variable was done among peak oxygen consumption per bodyweight, age and presence of acute-phase congestive heart failure, only age and a history of heart failure remained as independent contributors to excessive ventilation. Peak $\mathrm{VO}_{2}$ was correlated well with age $(r=0.50)$.

\section{Discussion}

The major new findings of the present study are: (i) among 131 patients with acute myocardial infarction, 24 patients $(18 \%)$ had an excessive ventilatory response to exercise as assessed by the $\mathrm{VE}_{\mathrm{E}}-\mathrm{V}_{\mathrm{CO}}$ slope at 1 month after AMI; (ii) of the 24 patients with an excessive response, 15 patients $(63 \%)$ showed a significant improvement in ventilatory response within 4 months; (iii) the $\mathrm{VE}-\mathrm{V}_{\mathrm{CO}}$ slope value at 1 month after AMI independently was correlated positively with age and was greater in patients with a history of acute phase heart failure; and (iv) conversely, an improvement in the $\mathrm{VE}-\mathrm{V}_{\mathrm{CO}}$ slope did not correlate with the variables of exercise capacity nor hemodynamics.

\section{Previous Studies}

Worsened ventilatory response to exercise and its improvement have been reported in patients with atrial fibrillation and after conversion; ${ }^{11}$ cardiomyopathy and after transplantation $;{ }^{8}$ and with congestive heart failure ${ }^{2}$ and pulmonary disease with an improvement after rehabilitation $!^{10}$ However, to our knowledge, excessive ventilation in patients after AMI and an improvement within 4 months have not been reported.

\section{Possible Mechanism of the Excessive Ventilatory Response and Its Improvement}

Age Age was independently related to excessive ventilatory response after AMI. The normal values of the $\mathrm{VE}-\mathrm{V}_{\mathrm{CO}}$ slope used in the present study were based on a population that was aged $52 \pm 17$ years, which is much younger than the average age of patients who participated in the present study. In addition, patients in the excessive ventilatory group were older than patients in either the intermediate or normal group. Therefore, age is related to exercise hyperpnea at 1 month after AMI. But more excessive ventilation was improved further in 4 months, meaning that the improvement is not related to age and is brought

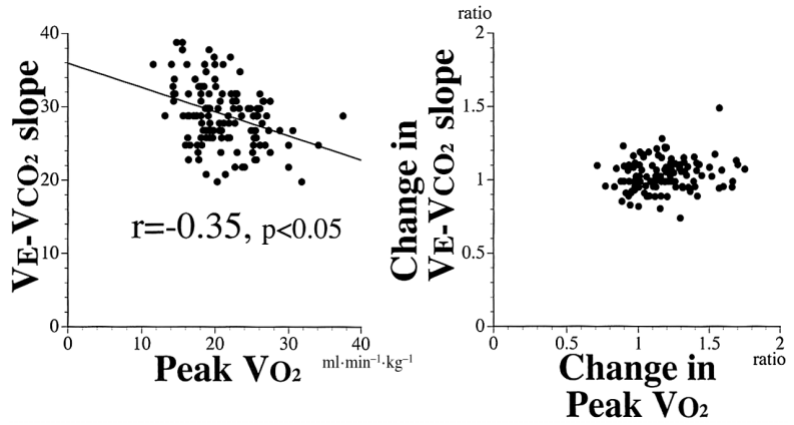

Fig 5. Change in relationship between peak $\mathrm{VO}_{2}$ and the $\mathrm{Ve}-\mathrm{V}_{\mathrm{CO}}$ slope. The left panel shows the relationship at 1 month after AMI. The right panel shows the relationship between improvement at 1 and 4 months after AMI. The improvement is represented as the ratio of the value at 4 months compared with the value at 1 month after AMI.

about by another mechanism, such as the effect of excercise.

Hemodynamic Factor According to Sullivan, the ventilatory response in terms of the $\mathrm{VE}_{\mathrm{E}}-\mathrm{VCO}_{2}$ slope was determined by anatomical and physiological $\mathrm{VD}_{\mathrm{D}} / \mathrm{VT}_{\mathrm{T}}^{5} \mathrm{~A}$ physiological cause of an increase in $\mathrm{VD}_{\mathrm{D}} / \mathrm{V}_{\mathrm{T}}$ may be associated with ventilation-perfusion $\left(\mathrm{V}_{\mathrm{A}} / \mathrm{Q}\right)$ mismatch. $\mathrm{VE}_{\mathrm{E}} / \mathrm{VCO}_{2}$ is theoretically determined by $\mathrm{VD}_{\mathrm{D}} / \mathrm{VT}_{\mathrm{T}}$ and $\mathrm{PaCO}_{2}$, but is mostly dependent on $\mathrm{VD}_{\mathrm{D}} / \mathrm{VT}_{\mathrm{T}}$ because hyperventilation disappears and $\mathrm{PaCO}_{2}$ is changed little when exercise is in progress? In the case of converted atrial fibrillation, cardiac output should increase, resulting in reduced $\mathrm{VD}_{\mathrm{D}} / \mathrm{V}_{\mathrm{T}}$ and improved ventilatory response ${ }^{11}$ Also, patients who received cardiac transplantation may be able to reduce excessive ventilation by increasing cardiac output and decreasing high pulmonary arterial pressure? Thus, improvement in the ventilatory response in patients with converted atrial fibrillation and cardiac transplantation are mainly caused by central hemodynamic change.

In the present study, the fact that the hemodynamic parameters such as left ventricular ejection fraction and enddiastolic pressure or the presence of congestive heart failure did not correlate with an improvement in the $\mathrm{VE}-\mathrm{V}_{\mathrm{CO}}$ gradient suggests that improved hemodynamics may not be the main reason for the reduction in excessive ventilation. However, patients with acute phase congestive heart failure had a more excessive ventilatory response, suggesting that hemodynamic abnormality may contribute to hyperpnea at 1 month after AMI. As an increase in physiological dead space and the resulting exercise hyperpnea is caused by pulmonary hypertension and pulmonary diseases? subclinical pulmonary hypertension or congestion leading to respiratory abnormality, which acute phase congestive heart failure gives rise to, may remain and contribute to excessive ventilation. After 4 months after AMI, hemodynamic improvement and increased pulmonary perfusion might contribute to improved ventilation-perfusion relationship and decreased $\mathrm{VE}_{\mathrm{E}}-\mathrm{V}_{\mathrm{CO}}$ slope.

Muscular Effect Mancini suggested that muscular changes are connected with ventilatory improvement ${ }^{13}$ However, in the present study, the improvement in excessive ventilation did not correlate with an improvement in exercise capacity, which is considered to be related to an improvement in muscular oxygen utilization (peripheral effect). This suggests that peripheral changes may not be associated with an improvement in excessive ventilation.

Davey et al claimed that the training effect may be 
attributable to changes in the control of ventilation through changes in chemo- and mechanoreceptors in the legs of patients with congestive heart failure with rehabilitation? They pointed out that minimum $\mathrm{VE}-\mathrm{VCO}_{2}$ (another index of excessive ventilation) correlated with exercise time and that this fact supported the importance of the muscular effect on the improvement of ventilatory response. In the present study, peak exercise capacity and $\mathrm{VE}_{\mathrm{E}}-\mathrm{V}_{\mathrm{CO}}$ slope were significantly correlated but the degree of improvement in both parameters did not correlate, indicating that peripheral improvement was not an important mechanism for ventilatory improvement. One study demonstrated that a coupling of $\mathrm{VE}$ and $\mathrm{VCO}_{2}$ was not abnormal in patients with complete spinal cord transmission, denying that muscular stimuli to ventilation was strong enough! 14

Hypersensitivity for Excessive Ventilation Niederman argued that desensitization of patients to dyspnea was the reason for reduced ventilatory need after rehabilitation in patients with obstructive lung disease in conjunction with improved respiratory muscle function ${ }^{10}$ Chua demonstrated that enhanced hypoxic and hypercapnic chemosensitivity played an important role in excessive ventilatory response in patients with chronic heart failure. 15 Patients with poor exercise habits have high $\mathrm{CO}_{2}$ sensitivity, leading to excessive ventilation and early dyspnea. Exercise therapy makes them tolerable to exercise hypercapnea and more capable of taking high-intensity exercise. Therefore, hypercapnic hypersensitivity and its normalization would be another potential explanation for the exacerbation and improvement in ventilatory response.

\section{Worsened $\mathrm{VE}_{\mathrm{E}}-\mathrm{V}_{\mathrm{CO}}$ Slope}

The $\mathrm{VE}-\mathrm{VCO}_{2}$ slope was aggravated in 10 patients including 5 in the normal $\mathrm{VE}-\mathrm{VCO}_{2}$ slope group, 2 in the intermediate group and 3 in the excessive group, 4 months after acute myocardial infarction. The average age of patients in this group was 64 years. They had an ejection fraction of $43 \%$, maximal creatine kinase value of 4,933 , and an average of $10 \%$ increase in exercise capacity. Seven patients had anterior myocardial infarction. All of these values imply that the patients were older, there was a higher incidence of myocardial infarction (including more cases of anterior infarction), and showed less improvement in exercise capacity when compared to the average values of the patients in the series. Therefore, the aggravated $\mathrm{VE}-\mathrm{VCO}_{2}$ slope might be ascribed to several factors such as observational error; unimproved $\mathrm{CO}_{2}$ sensitivity due to insufficient exercise training; hemodynamic deterioration caused by left ventricular remodeling after myocardial infarction, which may be most plausible.

\section{Study Limitations}

Although those patients who participated in the rehabilitation program after AMI were routinely tested for their exercise ability before and after exercise therapy, we did not compare their improvement in excessive ventilation with that in patients who did not undergo any exercise therapy; hence, we cannot conclude whether this effect was related to exercise therapy or not. We can argue that excessive ventilation after AMI was brought about by deranged cardiac function, based on the result that more patients with acute heart failure had greater excessive ventilation and that it was improved in the recovery phase of AMI including during exercise therapy. Further studies are necessary to clarify which mechanism improves excessive ventilatory response to exercise.

In the present study we did not measure respiratory function with both the exercise tests. Therefore, we cannot completely deny the possibility of improved respiratory function as a mechanism for an improvement in excessive ventilation. In addition, neither respiratory muscle work nor deoxygenation was assessed.

\section{Clinical Implications}

In the present study, a greater fraction of patients in the excessive ventilatory response group showed improved responses compared to the other 2 groups, and the relative improvement correlated with the severity of excessive ventilation after AMI. This implies that it may be possible for patients with originally impaired ventilatory response to exercise more comfortably and with less sense of dyspnea at 4 months after AMI. This effect might be one of the benefits of exercise in patients with AMI.

\section{Acknowledgment}

We thank Dr Nakanishi at the National Cardiovascular Center in Japan for his useful suggestions.

\section{References}

1. Whipp BJ: Ventilatory control during exercise in humans. Ann Rev Physiol 1983; 45: 393-413

2. Metra M, Dei Cas L, Panina G, Visioli O: Exercise hyperventilation, chronic congestive heart failure, and its relation to functional capacity and hemodynamics. Am J Cardiol 1992; 70: 622-628

3. Kleber FX, Vietzke G, Wernecke KD, Bauer U, Opitz C, Wensel R, et al: Impairment of ventilatory efficiency in heart failure: Prognostic impact. Circulation 2000; 101: 2803-2809

4. Wasserman K, Hansen JE, Sue DY, Casaburi R, Whipp BJ: Measurements during integrative cardiopulmonary exercise testing. In: Principles of exercise testing and interpretation. Philadelphia: Lea \& Febiger, 1994: 64

5. Sullivan MJ, Higginbotham MB, Cobb FR: Increased exercise ventilation in patients with chronic heart failure: Intact ventilatory control despite hemodynamic and pulmonary abnormalities. Circulation 1988; 77: 552-559

6. Fink LI, Wilson JR, Ferraro N: Exercise ventilation and pulmonary artery wedge pressure in chronic stable congestive heart failure. Am J Cardiol 1986; 57: 249-253

7. Wasserman K, Hansen JE, Sue DY, Casaburi R, Whipp BJ: Pathophysiology of disorders limiting exercise. In: Principles of exercise testing and interpretation. Philadelphia: Lea \& Febiger, 1994: 80-94

8. Marzo KP, Wilson JR, Mancini DM: Effects of cardiac transplantation on ventilatory response to exercise. Am J Cardiol 1992; 69: 547-553

9. Davey P, Meyer T, Coats A, Adamopoulos S, Casadei B, Conway J, et al: Ventilation in chronic heart failure: Effects of physical training. Br Heart J 1992; 68: 473-477

10. Niederman MS, Clemente PH, Fein AM, Feinsilver SH, Robinson DA, Ilowite JS, et al: Benefits of a multidisciplinary pulmonary rehabilitation program. Improvements are independent of lung function. Chest 1991; 99: 798-804

11. Lundström T, Karlsson Ö: Improved ventilatory response to exercise after cardioversion of chronic atrial fibrillation to sinus rhythm. Chest 1992; 102: 1017-1022

12. Buller NP, Poole-Wilson PA: Mechanism of the increased ventilatory response to exercise in patients with chronic heart failure. Br Heart J 1990; 63: $281-283$

13. Mancini DM: Pulmonary factors limiting exercise capacity in patients with heart failure. 1995; 37: 347-370

14. Adams L, Frankel H, Garlick J, Guz A, Murphy K, Semple SJ: The role of spinal cord transmission in the ventilatory response to exercise in man. J Physiol (Lond) 1984; 355: 85-97

15. Chua TP, Clark AL, Amadi AA, Coats AJ: Relation between chemosensitivity and the ventilatory response to exercise in chronic heart failure. J Am Coll Cardiol 1996; 27: 650-657 